\title{
LA BIOGRAFÍA COMO INSTRUMENTO PARA EL ELOGIO DE UNA FAMILIA: LA CARTA SOBRE LA MADRE JOSEFA DE SAN JUAN BAPTISTA ${ }^{1}$
}

PILAR ZORROZUA

Es bien conocida la dificultad, casi imposibilidad, que entraña lograr el relato objetivo de una trayectoria vital y, en ocasiones, ni siquiera ese es el fin de una biografía. Un ejemplo extremo de la disparidad entre la vivencia del sujeto y la biografía de la que es objeto son las Cartas, los escritos obligados por la norma de algunas órdenes religiosas para notificar el fallecimiento de una hermana al resto de los conventos; su finalidad es que se realicen los oportunos sufragios por su alma y así se afirma en el párrafo con que finalizan todas ellas:

\begin{abstract}
«Y aunque tan religiosa vida, y prevenida muerte, debo juzgar prudentemente que ha sido de las preciosas delante de Dios: no obstante, cumpliendo con mi obligación, ruego a V.R. que ordene, se hagan a nuestra H. Baptista los sufragios acostumbrados según nuestros santos estilos de caritativa hermandad: y a mí, con toda mi Santa Comunidad, no me olvide V.R. en sus Santos Ejercicios y Oraciones» ${ }^{2}$.
\end{abstract}

Sin embargo, ya en el título de estas Cartas se indica que su contenido va más allá; además de su intención de comunicar se reconoce la pretensión de describir la «vida y venerables virtudes» de la fallecida. Teniendo en cuenta que el sujeto de la biografía es una religiosa que vivía dentro de la comunidad, la narración pretende prolongar su servicio a ésta convirtiéndola en ejemplo para sus hermanas a través de un elogio de conducta moral.

\footnotetext{
1 Este artículo se escribe en el marco de una investigación sobre la autobiografía de las religiosas españolas del siglo XVIII realizada dentro del IFES XVIII y gracias a una beca de formación de investigadores otorgada por el Gobierno Vasco.

2 Carta en que se da cuenta de la vida, muerte y virtudes de la Madre Josefa de S. Juan Baptista, religiosa profesa, a los conventos de la Hermandad, de su recolección y descalcez, la Madre Rosa de la Ascensión. Priora en su convento de Corpus Christi de Agustinas Descalzas de la ciudad de Murcia [1749]. Pág.14.
} 
Para cumplir con el propósito de ensalzar a la religiosa se describe su peripecia vital de acuerdo al paradigma de la perfecta entrega a Dios que se había formado a lo largo de la tradición cristiana y que se plasmaba en las hagiografías; así, cuanto más se acerquen los sentimientos atribuidos y los acontecimientos narrados a ese ideal, más elevado será el encomio. Dado que todos estos escritos se componen de acuerdo a un canon establecido por una larga tradición puede incluso llegar a considerarse la existencia de un subgénero, el de la Carta biográfico-religiosa de características definidas.

Considero característico de este subgénero la condición de religiosas de autora y lectora declarada, si bien puede suponerse que alcanzarían más amplia difusión. Se producen y reciben dentro de un círculo cerrado: las autoras se nutren de la lectura de Cartas semejantes, proponen a sus hermanas en religión un modelo deseable y tienen el propósito de ejemplarizar. El propósito de elogiar a la fallecida y servir de ejemplo a las otras religiosas es otro de los rasgos que lo caracterizan.

En cuanto al contenido he comprobado que se reiteran los acontecimientos que van desde los beneficios divinos a otros más cotidianos que subrayan virtudes como la obediencia. Esta colección de anécdotas se extrae de la Biblia, las obras de los Santos Padres y las hagiografías de santos ya reconocidos por la Iglesia. La narración se detiene en aquellas épocas vitales que se suponen más importantes en la vida de una religiosa: las primeras revelaciones de su vocación, la profesión, un breve repaso de su vida en el convento y, sobre todo, el período correspondiente a la enfermedad, tan vinculada a la experiencia mística. Se compone así una biografía-tipo, un retrato idealizado de la peripecia espiritual que carece de los detalles más privativos de una existencia particular.

Del mismo modo, comparten las mismas expresiones y figuras literarias extraídas de las obras autorizadas y aconsejadas para las mujeres: libros de espiritualidad o místicos, biografías de santos, manuales de oración, etc... Hay además, una clara preferencia hacia aquellas que pertenecen al campo de lo sensible tales como la luz, los olores y la naturaleza tanto vegetal como animal.

En lo que se refiere a las que se escriben durante el siglo XVIII su lectura desvela que evolucionan a la par que el pensamiento y el gusto durante ese periodo: en lo ideológico se elimina progresivamente las referencias a lo sobrenatural, tales como sucesos milagrosos e intervenciones demoníacas, limitándose cada vez más a los hechos verificables; en lo estilístico recorren el camino que va desde el gusto por lo retórico y lo argumentativo a otro más simple que huye de las figuras literarias para concentrarse en la narración desnuda de sucesos. Pero incluso en un texto de características tan establecidas pueden encontrarse rasgos peculiares que obedecen a la singularidad del estilo de la redactora, a la relación que le 
une al sujeto de la Carta (cuanto más estrecha sea se introducirán más elementos extraños al paradigma, como la inteligencia) y a la altura espiritual que quiera atribuirse a la fallecida ${ }^{3}$.

Para mostrar cómo estas tres cuestiones determinan la construcción de una Carta, son ejemplares las que escribe la agustina Madre Rosa de la Ascensión [1675-1757], que llegó a ser priora del convento de esa orden de Murcia, lo que le obligó a componer al menos tres de estas Cartas. Esta religiosa se distingue de otras por su ambición intelectual que le lleva a encargar la biografía de la Madre fundadora.

En dos de las Cartas que escribe, la primera ${ }^{4}$ y la tercera ${ }^{5}$, destacan la cercanía personal con la fallecida (la primera se ocupa de su propia tía) y la importancia jerárquica de ésta en el convento; la proximidad determina un conocimiento más íntimo, lo que conlleva la aparición de más anécdotas personales, y sus cargos de responsabilidad, en cuanto suponen un alto grado de perfección espiritual, obligan a reiterar cada uno de los sucesos recogidos en las hagiografías, incluso los milagros.

Estas dos circunstancias, relación personal e importancia en la jerarquía conventual, se reflejan tanto en la extensión desmedida de estas dos Cartas (31 y 139 páginas respectivamente), como en el trabajado estilo de la Madre Rosa. En líneas generales, éste se caracteriza por reducir al mínimo la narración de sucesos de carácter probatorio centrándose en disquisiciones teóricas sobre las virtudes ${ }^{6}$ que define de acuerdo a la doctrina.

3 En otro artículo («Las Cartas, entre la biografía tópica y la expresión personal: El caso de la Venerable Madre María Rosa de la Ascensión», Dieciocho, Spring, 2000) abordo un aspecto que también depende de la autora: la conciencia personal sobre su labor, es decir, si se reconoce como escritora o sólo como simple instrumento de una tradición a la que no pretende aportar rasgos personales. La diferencia se plantea entre aquellas que se reconocen autoridad personal para formular comentarios doctos, enjuiciar lo narrado por sí misma e introducir recursos literarios originales y las que se limitan a reiterar los testimonios de los confesores y las figuras tópicas de las hagiografías.

Carta que escribe la Madre Priora del convento de las Agustinas Descalzas de la ciudad de Murcia a las Madres prioras de los conventos de Hermandad, dando noticias de la religiosísima vida y singulares ejemplos de virtudes de la venerable Madre Antonia de la Purificación, y pidiendo se hagan los sufragios por su alma [1741]. Archivo Municipal de Murcia. Sgn.:1-E-25 (5).

5 Carta en que se da cuenta de la vida, muerte, y virtudes de la M. Eugenia María del Espíritu Santo, religiosa profesa, a los conventos de la Hermandad de su recolección y descalcez, la Madre Rosa de la Ascensión. Priora en su convento de Corpus Christi de Agustinas Descalzas de la ciudad de Murcia. [1749]. Archivo Municipal de Murcia. Sgn.: 10-F-8 (2).

6 «[...] avivó en ella la virtud de la esperanza segunda entre las Teologales, por la cual el alma aspira a conseguir el sumo bien, que conocía por la Fe ser su único centro, esperando la Bienaventuranza con los medios para conseguirla. Y como estos medios supuestos los méritos de Cristo, son la gracia de Dios, y las buenas obras, la que por todo el resto de su vida seglar, y religiosa practicó obras tan santas como llevo dicho, y acaudaló tanta gracia:[...]» Carta [...],de la venerable Madre Antonia de la Purificación[...]. Pág. 26. 
Además, la reiteración de temas ${ }^{7}$ y figuras retóricas con las que pretende aumentar el elogio provoca que sus textos resulten confusos y lentos. Como último rasgo, cabe destacar que, aún siendo mujer, la Madre Rosa de la Ascensión se arroga en estas dos Cartas la autoridad necesaria para abordar cuestiones religiosas de gran sutileza. Para hacerlo establece la superioridad del conocimiento intuitivo, logrado mediante el don que Dios le otorga por su mérito personal ${ }^{8}$, sobre el adquirido en los libros, prohibido para las mujeres:

\begin{abstract}
«Fue tan superior el don de contemplación, que el poder divino echó en nuestra Venerable Madre Antonia sobre la Oración, y repetición de actos, que por toda su vida ejercitó meritoriamente para su mayor aprovechamiento, que muchas veces a la primera vista, simple conocimiento, que tenía en su oración de alguno de los atributos de Dios, como de su Inmensa Bondad, Hermosura, grandeza, Sabiduría, Majestad, o Finezas de la majestad de Jesucristo en su Encarnación, Nacimiento, o alguno otro Misterio de su Vida, Santísima Pasión, y Muerte, era tan clara la lumbre del Cielo, con que esto se le proponía, como si viera, tocara, o experimentara las divinas perfecciones: y por tanto, quedaba en estas ocasiones su entendimiento como un Sol coronado de Luces, más instruido de este claro conocimiento, que de cuantos pudiera con diligencias, aplicación a los Libros, discursos, o consideración adquirir su industria» ${ }^{9}$.
\end{abstract}

La segunda Carta en orden cronológico, Carta en que se da cuenta de la vida, muerte, y virtudes de la Madre Josefa de S. Juan Baptista, religiosa profesa a los conventos de la Hermandad, de su recolección y descalcez, la Madre Rosa de la Ascensión, Priora en su convento de Corpus Christi de Agustinas Descalzas de la ciudad de Murcia $[1749]^{10}$ tiene características totalmente diferentes.

En esta ocasión la autora se limita a cumplir con la norma de comunicar la muerte como lo demuestran su brevedad, sólo 14 páginas, y la renuncia por parte de la Madre Rosa a sus rasgos estilísticos más característicos: no se repite el elogio de una virtud, no relata sucesos sobrenaturales ni testimonios del confesor, tampoco argumenta sus afirmaciones y, finalmente, evita reclamar la autoridad que le permite entrar en sutilezas teológicas; en suma, la elaboración personalizadora del texto desaparece totalmente.

Estos rasgos se justifican por la inexistencia de una relación personal y el carácter vulgar de la religiosidad de la Madre Josefa de San Juan

\footnotetext{
7 Sirva como ejemplo la constante referencia al ejercicio de la oración como sustento de las demás virtudes.

8 Ese acceso a la sabiduría, libre de las restricciones impuestas a las féminas, permite que mujeres iletradas escribiesen sus experiencias y las de otras religiosas obteniendo cierto respeto.

9 Carta [...], de la venerable Madre Antonia de la Purificación[...]. Pág. 22.

10 Archivo Municipal de Murcia. Sgn.:10-F-8 (1).
} 
Baptista, que parecía carecer de la gracia divina y la virtud que la hubieran hecho acreedora de las más altas dignidades; tal es así que la descripción de su carrera conventual apenas es un paréntesis acotado del texto ${ }^{11}$ frente a la prolija enumeración de otros casos.

Este texto, pese a su escaso valor, encuentra justificación para ser publicado en un objetivo único entre las Cartas que he estudiado: servir como instrumento para elogiar a las cuatro hermanas de la fallecida, generosas patronas del convento. Éste es el propósito final que se establece desde el primero de los siete capítulos en que se divide la Carta.

En él, tras un párrafo inicial que comunica su muerte ${ }^{12}$ y resume las circunstancias del fallecimiento, se dedica a resumir su vida en el período previo a su ingreso en el convento con ocho años. De sus tres párrafos dedica los dos primeros a subrayar la pertenencia a una familia distinguida tanto por su devoción como por la riqueza material ${ }^{13}$, rasgo habitual de estas biografías, y sólo el último a la fallecida. La redactora considera de interés dejar constancia de los ventajosos enlaces de las cuatro hermanas, de un total de seis, que tomaron estado en el siglo:

\begin{abstract}
«Las cuatro hicieron acertada elección de estado seglar, con sujetos correspondientes en calidad, y prendas. La primera, y mayor de todas Doña Inés de Quiroga y Contreras, con el Señor Don Tomás Melgarejo, que después de Beca Mayor en Salamanca, fue honroso lustre de su Toga en Tribunales mayores, hasta el Supremo Consejo de Castilla. La segunda Señora Doña Felipa de Quiroga, con el Ilustrísimo Señor Conde de Canillas. La tercera Señora Doña María de Quiroga, con el Señor Don León Espino, que a su nobleza añadió su bizarría, Cristiandad, y valor muchos esmaltes con la adquirida en los Ejércitos nuestros, hasta merecerse los grados mayores de Brigadier, y Mariscal de Campo. La cuarta Señora, Doña Micaela de Quiroga, con el Señor Don Pedro de Castañeda, Marqués de Peña Serrada, que hoy viven, actual Corregidor de la Ciudad de Toro» (4) ${ }^{14}$.
\end{abstract}

La desproporción entre los datos personales que conocemos sobre ella y los que se nos proporcionan sobre sus hermanas señala el verdadero papel que la religiosa desempeña en su propia biografía y que buena parte de su relevancia se desprende de la categoría social alcanzada por su familia.

La Madre Baptista vivirá en el convento como una religiosa más, sin que su espíritu, sujeto real de estas biografías, destaque ni por recibir ins-

\footnotetext{
1 «Así en todas las obediencias, (que se empleó la Hermana Josefa de Refitolera, Enfermera, Ropera, Portera y Sacristana)[...]». Pág.6.

12 A los sesenta y dos años, tras cincuenta y cuatro en el convento.

13 «Nació[...], de padres muy afortunados a lo del Mundo y muy felices a lo del Cielo. Los Señores Don Juan Francisco Suazo de Quiroga y Contreras, del Orden de Calatrava, y veinticuatro de Granada, y Doña María de Yepes y Rojas, dichosos padres de la Hermana Baptista, juntaron al antiguo notorio lustre de su sangre en los reinos de Jaén, y Murcia, la abundancia de muchos bienes». Pág.4.

${ }_{14}$ Entre paréntesis indico la página en que se encuentra la cita.
} 
piración divina ni por su perfección. Ésta es la causa de su brevedad: ya que se requiere hacer el elogio de una vivencia espiritual no excepcional, el modelo de referencia no será el hagiográfico lo que le permite omitir algunos de los sucesos tópicos propios de éste, como visiones, milagros y otras anécdotas en el ejercicio del sacrificio, la mortificación, la oración, la iluminación divina, etc...

Es en el primer capítulo donde se establece el carácter común de la religiosidad de la Madre al describir el nacimiento y desarrollo espontáneo de una vocación bendecida por sus padres. La placidez con que esto sucede hace imposible e innecesaria la narración de las anécdotas propias de una biografía cercana a la santidad habituales en otras Cartas. No hay en ésta llamada de Dios y tampoco puede extenderse en el modo en que se forzó la voluntad opuesta de los padres, ya sea con una enfermedad en la futura religiosa o con la muerte del progenitor más reacio.

La misma medianía justifica que el elogio se circunscriba a las cualidades mínimas exigibles a una religiosa que se reiteran como lugares comunes en estos escritos. Así, en la etapa de novicia se destaca, como en otras muchas Cartas, un extremo rigor personal que se verá obligada a moderar tras la profesión. Ya como profesa se valoran algunas cualidades comunes como la apacibilidad, la devoción, la afición a todo lo bueno y la dulzura en el trato sin distinción entre las hermanas ${ }^{15}$; como aportación personal la autora incluye el odio al ocio como una virtud ${ }^{16}$ :

«Enemiga declarada del ocio, que es̀ madre de muchos vicios, y enemigo de toda virtud» $(6)^{17}$.

Finalmente, para ajustarse a esa religiosidad media, omite las referencias a las virtudes más elevadas, las cardinales y teologales, para ocuparse solamente de los votos, cuya observancia supone el mínimo de virtud exigible a las religiosas. Hace de ellos un somero repaso sin añadir ni anécdotas probatorias ni testimonios de testigos que doten de singularidad, aunque fuera mínima, a esta mujer. Describe su pureza y obediencia con un

15 La insistencia en esta cualidad revela las pequeñas rencillas en el convento y las indeseables amistades particulares que impiden la completa dedicación a Dios, como se subraya en otras cartas.

16 Esa aversión será predicada por los ilustrados como la virtud laica más deseable para la mujer, manteniendo con un nuevo soporte ideológico los mismos valores tradicionales para un importante sector de la población.

17 En la carta que escribe sobre su tía (Carta [...], de la venerable Madre Antonia de la Purificación [...]) recoge expresiones semejantes, incidiendo en uno de sus temas favoritos sobre la vida en el siglo: «Y penetrando ya el parentesco, que el ocio tiene con tantos males en los pocos años, lo miraba con mortal ojeriza, según huía de estar ociosa:[...]». Pág. 2. «Por esto fue enemiga jurada del ocio, origen de todos los males, y amiga íntima del trato familiar con Dios; $[\ldots] »$. Pág. 18. 
ejercicio de estilo literario al que no acompaña la argumentación teológica habitual en su autora:

«La Pureza, como de ángel, sin resabios de humana; porque Dios la rodeó de simplicidad columbina, y un candor todo divino» (6).

«Así, en todas las obediencias, [...] e embebía tanto en aquello, que la tocaba, que tocaba ciertamente (en cuanto veíamos) todos los puntos, más altos de esta virtud.[...]. Y su voluntad amaba y gustaba tanto de lo que obedecía, que obedecía amando con toda su voluntad» (6).

Subrayando el que considero verdadero objetivo de esta Carta se extiende en la pobreza, no tanto para elogiar la suya, como para ensalzar la generosidad sin límites de sus hermanas:

«Como la Casa de la Hermana Baptista, sobre ser muy abastada, fue de notoria antigua nobleza; fue muy consiguiente que las Hermanas seglares tuviesen destinos proporcionados con sujetos de carácter, y de las mismas circunstancias.[...]

Parece la conocieron presto el genio, inclinación, y gusto: y por decir de una vez, cuanto le dieron, y quisieron dar; basta decir, que tenían puesta letra abierta para todo cuanto boquease la hermana Baptista, que luego se la hubiese de entregar» (7).

En el mismo sentido se subraya el aprecio de la comunidad a la generosidad de sus hermanas:

«No habiendo Oficina alguna, por cuantas pasó, que no la dejase señalada con alguna buena memoria de su cariño, y de la liberalidad de sus señoras hermanas» (7).

En el capítulo cuarto se reitera el encomio a las patrocinadoras a través de la descripción de la devoción de la fallecida al Señor Sacramentado y a San José. Para referir esta predilección de la hermana Baptista se recogen algunas evidencias visibles ${ }^{18}$ y habituales en estos textos tales como los arrebatos amorosos, la comunión casi diaria y el especial adorno con que mantenía sus altares cuando era Sacristana. Es en el aspecto puramente material donde interviene de nuevo su familia contribuyendo a la talla y dorado del retablo del Santo y a la lámpara de plata:

«De manera, que sino todo lo que hoy es, el Altar magnífico del Señor San José fue desvelo y cuidado de la Hermana Josefa: es preciso confesarla, como principalísima bienhechora, y a sus Señoras hermanas, como parte principal de este todo, nuestra gratitud» (8).

18 La autora no puede explicar los aspectos más íntimos de esta veneración, puesto que las religiosas carecen de capacidad para juzgar el alma de la biografiada, potestad exclusiva del confesor. 
En este párrafo se hace un elogio a la generosidad familiar que se hará público con la impresión de la Carta; el panegírico de la fallecida se convierte así en un vehículo para ofrecer a su familia un halago público que respalda su posición económica y social.

Tras el encomio de su vida, salpicado de elogios a su familia, llega en el capítulo quinto a la descripción de la enfermedad que la conduce a la muerte. Su comportamiento en este punto también se ciñe al modelo de espiritualidad fijado: la abnegación ante un dolor sobrehumano y la asunción de la enfermedad y sus consecuencias como un regalo divino («finezas, y regalos del Cielo») ${ }^{19}$ inmune a remedios humanos.

Sin embargo, es el séptimo y último capítulo el que evidencia la precipitación y desinterés con que la Madre Rosa había emprendido este trabajo. Cumplido en buena parte el encomio familiar, termina apresuradamente su escrito recurriendo a los tópicos habituales en estas Cartas. En ese último capítulo resume las consideraciones sobre la mortificación, el silencio, el ayuno y la oración en párrafos apresurados:

«Pues como su vida de antemano había sido penitente mucho, en ayunos, vigilias y otras asperezas, además de las que señala nuestra Santa regla, y estilos; había sido devota, y fervorosa con Dios, en la oración vocal, y mental, haciéndolo todo con esmero, y perfección» (12).

«El silencio, aun con sus mismas Hermanas, y en medio de tantas penas; fue esmerado: pues siempre la $\mathrm{H}$. Josefa fue de pocas, aunque bien medidas, palabras» (12-13).

«La mortificación fue muy particular; lo primero en lo exterior, en tanto imponderable padecer. Lo segundo en lo interior, en aquel tomar todo cuanto la diesen sin repugnancia;[...]» (13).

Habitualmente es en este momento cuando, con la obligada prudencia para no incumplir el mandato eclesiástico ${ }^{20}$, se insinúa la santidad de la biografiada al producirse sucesos milagrosos; éstos pueden ser bien la recuperación del sentido o el oído para poder tomar la comunión o ser oída en confesión, bien la conservación de su cadáver y el fervor popular que lleva a solicitar sus objetos como reliquias.

19 Pág. 12.

20 Un decreto del Papa Urbano VIII prohibía dar nombre de Santo o Beato a quien no lo hubiera recibido de la Iglesia. Así lo afirma la Madre Francisca de San Juan Evangelista en su Carta Misiva sobre la Vida y Heroicas Virtudes de la venerable Madre Rosa de la Ascensión, Murcia, Felipe Díaz Cayuela, [1757]: «Por cuanto la santidad del Papa Urbano VIII, en su declaración del año de 1634, moderó la prohibición publicada por su anterior Decreto de 13 de marzo de 1625 de poderse imprimir vida, milagros, y favores sobrenaturales de cualquier persona, que haya muerto con opinión de santidad, sin examen y aprobación del Ordinario, consulta con la Sede Apostólica, y su juicio, y resolución mandó no se imprimiesen dichos libros, en que se dé nombre de Santo, o Beato a alguno asentando inmediatamente este nombre a la Persona sino a las costumbres, y opinión que de él se tuvo». 
En esta ocasión sólo a la redactora puede atribuírsele que se adhiera al modelo establecido incluyendo estas anécdotas tópicas que no son coherentes con el carácter mediocre, carente de favor divino, que venía atribuyendo a la religiosidad de la Hermana Baptista:

«[...] plugo a su divina providencia conservarla despejados todos los sentidos para que más sintiera, y todo su juicio, y razón para que así mereciese más, en los muchos actos de $\mathrm{Fe}$, Esperanza, Caridad, y resignación que ejercitó hasta el último respirar» (13).

«[...] habiendo desaparecido con la muerte, no sólo la palidez del rostro, y restituidose a su antiguo agrado, sino desterrándose todo el pestilente hedor del Gangrenismo: como que el favor que en Región más feliz, empezaba a gozar su dichosa Alma, quería Dios con especial privilegio, se comunicase a su afligido, y quebrantado Cuerpo» (14).

Un elemento no común a otras Cartas, y que subraya la especificidad de ésta, es la intervención de la familia en los funerales, inusual para las religiosas:

«Por complacer a los santos deseos, y ternuras de las Señoras hermanas, que todo lo tenían prevenido con su fineza, permití, que el funeral fuese según su gran liberalidad: continuando después Comunidades en venir sucesivas, a cantar Misa, y Responso por la Hermana Josefa» (14).

La Madre Rosa de la Ascensión subraya la liberalidad de sus hermanas y, además, la deuda moral que tiene contraída con ellas, razón por la que les permitiría intervenir en el entierro de la Hermana Baptista. Esa misma deuda es la razón que le obliga a dejar testimonio de su desprendida atención para con el convento utilizando para ello la Carta dedicada a su hermana; ésa es también el motivo por el que dedica uno de estos escritos a alguien inferior en lo espiritual, restringiendo ampliamente el contenido habitual de estas biografías de más elevadas pretensiones.

Esta medianía, su evidente falta de interés personal y la necesidad de satisfacer el orgullo familiar de quienes se habían convertido en generosas proveedoras del convento, justifican el estilo del texto: una Carta breve y estructurada sobre tópicos que nos dice más sobre las hermanas seglares de la fallecida que sobre ella misma. 